\title{
THE IMPACT OF FEMALE BUSINESS LEADERS ON THE Performance of Listed Companies in South Africa
}

\author{
Mkhethwa Mkhize
}

Wits Business School, University of Witwatersrand

Pumela Msweli

Graduate School of Business Leadership, University of South Africa

Accepted November 2010

\begin{abstract}
The purpose of this study is to determine the impact of female business leaders in JSE-listed companies on the financial performance of those companies. This is as result of the proposition that women, over and above men, bring unique skills to the workplace. However, it is hypothesized in this study that JSE-listed companies led by a high percentage of women do not outperform similar companies led by a low percentage of women. The Lean Modigliani and France Modigliani measure $\left(\mathrm{M}^{2}\right)$ was used to test this hypothesis. Results of this study indicate that companies led by women do not outperform similar companies led by men. As a result, the null hypothesis is not rejected. Implications of these results are discussed.
\end{abstract}

Key words: financial performance, female business leaders, business women, employment equity.

JEL M50, P47

\section{1}

\section{Introduction}

The introduction of the Employment Equity Act has resulted in an influx of females into the workplace. For example, as reported in the Business Women's Association Census (2007:16), 42.9 per cent of total employed population in the Republic of South Africa are women. This success is partly as a result of a legal reform in the labour market and employment equity compliant employers. It could be implied that South African employers are starting to acknowledge the urgent need of fully utilising all of the human capital. Claes (1999) summarises special benefits of recruiting, training and retaining females in senior management positions. He argued that women, over and above men, bring the following skills to the workplace: caring for fellow employees, an appreciation for teamwork, intuitive decision making and a sense of social responsibility. However, while 42.9 per cent of the total employed population are females, there are serious concerns that females are under-represented at the top management level. Baxter (2007) argues that the statistics show that women in leadership and executive positions are still nowhere near representative of the potential female workforce. In fact, most of the top positions are still occupied by men. 'Most organisations have moved towards equal representation in their employment equity status, but the same can seldom be said of their management and executive positions' (Baxter, 2007:81).

The purpose of this study is to determine the impact of female business leaders in JSElisted companies on the financial performance of those companies. Specifically, this study aims to determine if there are additional financial benefits derived from appointing a female at senior management level as initially suggested by Claes (1999) and Joy and Wagner (2007). The sub-objective is to formalise a new way of maximising shareholder's wealth, that is increasing the number of females in higher management 
positions especially in industries or sectors that are male-dominant.

\section{2}

\section{Review of related literature}

In terms of employment equity policies and guidelines, female candidates should be preferred to their male counterparts. In other words, authorities in South Africa fully understand the need to urgently address gender imbalance in the labour market, especially at the top management level. Some companies have already implemented a plan to break the glass ceiling by recruiting, training and retaining females in business leadership positions. According to the Federal Glass Ceiling Commission, the glass ceiling effect can be defined as an unseen barrier that keeps women and minorities from rising up the corporate ladder regardless of their achievements and qualifications (Cotter, Hermsen, Ovadia \& Vanneman, 2001). Cotter et al. (2001) explain that the inequalities in gender and race facing this barrier cannot be explained by any variables of education, experience, abilities, motivation, and other jobrelevant traits.

According to Maume (2004), as reported in Mathur-Helm (2006), failure of women and other minority groups in climbing up the corporate ladder, despite seeing the top jobs but still not reaching them due to discriminatory barriers, is what many think of as the glass ceiling. Mathur-Helm (2006) argue that the glass ceiling, considered a myth by many, is real and is nurtured by the organisational culture, policies and strategies besides women's own inadequacies. McDonald and Hite (1998) argue that socialisation, stereotyping and prejudice are some of the many underlying causes of the glass ceiling. Only the decentralised organisations, characterised by a culture that supports women's top positions, will help in breaking down the glass ceiling, along with women's effort to grow, develop and empower themselves through academic and career development (Mathur-Helm, 2006).

Dimovski and Brooks (2006) critically analysed the change in the gender composition of the boards of large Australian companies after public listing. Results of their study show no significant change in the proportion of male and female directors holding directorships at the time of the initial public offer (IPO), and some five to eight years later when the company is recorded as a top 500 company (by market capitalisation) on the Australian lists. This implies that the capital market is generally satisfied with the gender composition of boards from the time of the IPO. Bernadi and Weippert (2002) examined the differences in presentation of boards of directors in annual reports. The results of their study indicate that firms with a higher percentage of women on their boards signal this fact to shareholders, potential investors and other stakeholders by including pictures of their boards in their annual reports. Implications are that management recognises the value that is created by employing women into higher positions and they claim this value by publishing in their annual reports that they have recruited, trained and retained women in executive positions.

Employment equity programmes (EEPs) were conceived to eradicate employment discrimination, and organisations subjected to the Employment Equity Act, are mandated to adopt them (Leck, 2002).

Although a few women are in leadership positions, employers in South Africa have come to realise that they neglect managerial talent in nearly half of their workforce if they do not appoint women to such positions. For example, women constituted only 14.7 per cent of all executive management and only 7.1 per cent of all directors in 2004; in 2006 these numbers for both executive management and directors had increased to 16.8 per cent and 11.5 per cent respectively (BWA, 2007). Some scholars argue that this is as a result of feminine qualities of women, such as relationship building and teamwork that are valued in a more collaborative and creative management environment (Claes, 1999).

Given the results of the BWA's annual surveys (2004 to 2007), the number of women in top management positions is still below that of men. This could suggest that gender equality programmes have no substantial effect on female representation in 
leadership positions and that these programmes are symbolic rather than effective. However, a more appealing reason is that employment equity policies, in addition to the empowerment of women, clearly state that Africans should be given first priority. As a result, low numbers of women in top management positions may be due to the fact that organisations are focusing on targeting and developing Africans (male and female) for leadership positions.

An interesting research article by Joy and Wagner (2007) shows that, according to return on equity, companies with more women board directors outperformed those with the least by 53 per cent. Their study also shows that, according to return on sales and return on invested capital, companies with more women board directors outperformed those with the least by 42 per cent and 66 per cent respectively. These results support propositions by Baxter (2007) that women bring an added dimension to the workplace because they have a unique management approach that adds significant value to the business. Baxter (2007) adds that women are more intuitive and, in an age where business are increasingly realising that an intelligent approach to people management is needed in the drive towards greater efficiency and productivity, women are able to tap into their feminine side and bring out the best in people [adapted].

For South Africa, it could be argued that EEPs have resulted in some improvement in the number of women within the workforce, but their success, in terms of financial value, is yet not well known. As a result, it is the aim of this study to determine the financial performance of JSE-listed companies which are regarded as top performers in terms of recruiting, training and retaining women in top management positions.

\section{Data and data manipulation}

Permission to use the Business Women's Association (BWA) data set was granted by the BWA. The population was every company listed on the main board of the JSE Securities
Exchange South Africa (the JSE) as at 30 September 2006. The only companies that were excluded from the analysis by BWA are firms listed on the JSE but with all operations overseas or in other African companies; also excluded were companies that were suspended as at 30 September 2006. The implications are that companies listed on the Alternative Exchange, Development Capital or Venture Capital, were also excluded.

In order to control for the size effect, only the 25 largest JSE-listed companies by market capitalisation formed the sample size of this study. The top 25 companies (by market capitalisation) is a suitable sample because they match the market proxy used in study which comprises the largest companies (by market capitalisation). These 25 companies were classified in two groups in order to construct two portfolios using the following variables: Companies with 25 per cent or more of female directors were classified as 'highs'. The BWA refer to the highs as the 'top performing' companies: they were 'top performing' companies in the sense that they employed more female directors than other companies listed on the JSE, specifically because 25 per cent or more of their directors were women. Companies with female directorship less than 10 per cent were classified as 'lows'. The lows employed fewer female executives (if any) than other companies listed on the JSE. The share price data of the highs and lows over the study period of 1 October 2005 to 30 September 2006 was obtained from Profile Data. Profile Data is a reliable company that maintains a comprehensive database of all companies listed on the JSE.

The South African Reserve Bank (SARB) database was used to collect risk-free rate over the same study period. The 90-day Treasury bill was used as a risk-free asset. This bill is generally accepted by most financial economists as a risk-free asset proxy in South Africa. After realising that one of the highs became a public company in 2006 and its share price data started from June 5, 2006, this particular company was dropped from the list of highs. The All Share Index (ALSI) was used a market proxy. This proxy is generally regarded as the market portfolio on the JSE. 
Index prices of ALSI were supplied by the Market Data department of the JSE.

Fabozzi (1999) believes that the performance assessment process involves two main steps. The first step is performance measurement and the second step is performance evaluation. In other words, one cannot engage in performance evaluation without conducting an objective performance measurement exercise. Fabozzi (1999) adds that an evaluation process involves determining whether value is added by outperforming the well-established benchmark. For the purpose of this study, the All Share Index (ALSI) is used as a proxy for a benchmark. As reported in Msweli-Mbanga and Mkhize (2007), ALSI is regarded as one of the commonly-used market proxies (market) in the Republic of South Africa.

In order to measure performance, returns $\left(\mathrm{R}_{\mathrm{i}}\right)$ are computed by using a formula suggested by Affleck-Graves, Burt and Cleasby (1988). That formula is given as follows:

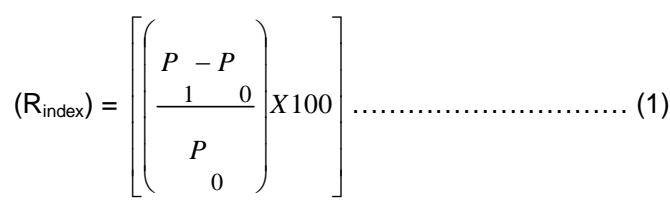

Where:

$\mathrm{P}_{0}=$ is the previous value of an index, and

$P_{1}=$ is the current value of an index.

Daily returns of individual companies are averaged to form a daily return of the highs. Similar procedure was repeated for the lows. In order to arrive at the effective risk-free rate over the study period, the repo rate at the beginning of a trading in October 2005 was rolled-over until the end of September 2006. In addition to this roll-over strategy, changes in this rate were effected.

\section{Hypothesis and research methodology}

As stated above, the purpose of this study is to determine the impact of female business leaders in JSE-listed companies on the financial performance of those companies. In order to achieve the purpose of this research paper, the following hypotheses are tested:

$\mathrm{H}_{0}$ : There is no difference between the financial performance of listed companies with 25 per cent or more women in leadership positions (highs) and the financial performance of listed companies with 0 per cent to 9 per cent women in leadership positions (lows).

In the alternative hypothesis:

$\mathrm{H}_{1}$ : There is a difference between the financial performance of listed companies with 25 per cent or more women represented in leadership positions (highs) and the financial performance of listed companies with 0 per cent to 9 per cent of women in leadership positions (lows).

Based on these hypotheses, an objective measure of financial performance is critical in order to achieve the purpose of this study. Fabozzi (1999) defines the Sharpe Index (SI) as a measure of the reward-to-risk ratio, and the risk of the share is measured by the standard deviation of the share. Bodie, Kane and Marcus (2005) argue that the attractive feature of the SI is that it divides the average return over the relevant time period by the standard deviation of returns over that period, thereby measuring the reward-to-volatility trade-off. Msweli-Mbanga and Mkhize (2007) used this methodology when they were determining the value added to the business by women. In their study, they pointed out that another study using a different research methodology was necessary in order to further investigate the role of women in leadership positions. They added that this was necessary because it is a neglected area of research. In addition to this, Bodie et al. (2005:869) argue that "while the Sharpe ratio can be used to rank portfolio performance, its numerical value is not easy to interpret'. As put forward by Bodie et al. (2005), a variant of Sharpe's measure was proposed by Graham and Harvey, and later popularised by Leah Modigliani and Franco Modigliani. This variant is known as the $\mathrm{M}$ squared $\left(\mathrm{M}^{2}\right)$ measure. In this study, $\mathrm{M}^{2}$ is adopted as a research methodology and summarised as follows: 
$\mathrm{M}^{2}=\left[e r f+\left(\frac{\operatorname{arp}-e r f}{\sigma p}\right) \sigma m\right]-\operatorname{arm} \ldots \ldots \ldots \ldots \ldots \ldots$

Where:

erf $=$ the effective return of a risk-free asset,

arp $=$ the average return of a portfolio (highs or lows),

$a r m=$ the average return of a market portfolio,

$\delta p=$ the standard deviation of a portfolio (highs or lows), and

$\delta m=$ the standard deviation of a market portfolio.

Standard deviation, not beta, is the appropriate measure of risk in this study because artificial portfolios, not real portfolios, are constructed for the purpose of this study. The higher the $\mathrm{M}^{2}$ measure of a portfolio, the better the performance of that portfolio. Implications are that companies will try to maximise this measure by recruiting, training and retaining female executives. Companies will do so because females are expected to improve financial performance of companies because they bring feminine attributes into a company like team spirit, caring, intuitive decision making and corporate social responsibility (Cutler \& Jackson, 2002).

\section{5}

\section{Results of the Study}

Table 1 (below) shows returns, standard deviations and $\mathrm{M}^{2}$ of portfolios and risk-free asset.

Table 1

Average Returns, Standard Deviations and $\mathrm{M}^{2}$ of Portfolios

\begin{tabular}{|c|c|c|c|c|}
\hline Portfolios & $\begin{array}{l}\text { Average } \\
\text { Returns }\end{array}$ & $\begin{array}{l}\text { Standard } \\
\text { Deviation }\end{array}$ & $\begin{array}{c}M^{2}(\%)= \\
\left\{e r_{f}+\left[\left(a r_{p}-e r_{f}\right) / \delta_{p}\right] \delta_{m}\right\}-\operatorname{ar}_{m}\end{array}$ & $\begin{array}{c}\text { Ranking according } \\
\text { to } \mathrm{M}^{2}\end{array}$ \\
\hline Highs & $17.7664 \%$ & 2.083910 & $1.16479 \%$ & 1 \\
\hline Lows & $14.0868 \%$ & 1.511386 & $0.54951 \%$ & 2 \\
\hline Risk-free & $6.70 \%$ & $\mathrm{n} / \mathrm{a}$ & $\mathrm{n} / \mathrm{a}$ & $\mathrm{n} / \mathrm{a}$ \\
\hline Market & $13.2601 \%$ & 1.454672 & $\mathrm{n} / \mathrm{a}$ & $\mathrm{n} / \mathrm{a}$ \\
\hline
\end{tabular}

According to Table 1 (above), returns of highs, lows, risk-free and market are 17.7664 per cent, 14.0868 per cent, 6.7 per cent and 13.2601 per cent, respectively. Table 1 displays standard deviations (not beta) of highs, lows and market as 2.0891, 1.511386 and 1,454672 respectively. Theoretically, the standard deviation of a risk-free portfolio is assumed to be zero. From these average returns and standard deviations, $\mathrm{M}^{2}$ of highs and lows are calculated and amounted to 1.16479 per cent and 0.54951 per cent respectively. The student t-test was performed and t-test results indicated that the p-value is far higher than 0.05 .

\section{6}

\section{Discussion and summary}

Results of this study show that listed South African companies with a high percentage of women in leadership positions do not outperformed similar companies with a low percentage of women in leadership positions.
In other words, the null hypothesis that there is no difference in the performance of companies led by women and those companies led by men, is not rejected. The results of this study indicate that companies have not, as yet, recognised the impact women have on the company's performance as a result of the feminine attributes they import into the organisation. These feminine attributes, namely caring, team spirits and intuition, are believed to improve the performance of the company. Put differently, it is believed that a new strategy to partly maximise owners' wealth is to recruit, train and retain capable women in leadership positions. This action will not only improve company's performance but will make a significant contribution to social development by redressing imbalances of the past.

Historically, women have been neglected in the labour market as a result of male-dominant practices which saw the role of a woman in the kitchen only. Sadly, most households in South Africa are headed by a woman who is usually 
the sole bread-winner. Therefore, empowering a woman is equivalent to empowering the whole nation. Consequently, appointing a woman into a leadership position could be thought of as a corporate social investment (CSI). South African government encourages the appointment of women into leadership positions by giving tenders to companies that, among other things, appoint women into senior management positions.

Disappointingly, the results of this study are inconsistent with the propositions by Baxter (2007) that women bring an added dimension to the workplace and that women are better managers of people and companies than their male counterparts. These results are also inconsistent with the findings of Joy and Wagner (2007). These authors concluded that companies with more women board directors outperformed those with the least women board directors over their study period. For the South African economy, the results of these studies are encouraging. Implications are that South Africa needs to create and maintain an enabling environment in order to realise the special benefits of appointing women into leadership positions.

The results of this study are consistent with conclusions drawn by Msweli-Mbanga and Mkhize (2007). Their findings suggested that the adoption of a policy to appoint women into leadership positions is not perceived to have a positive effect on the company's performance. Their study was based on data dating back to the year 2003, unlike this study which is based on data as recent as year 2006. This consistency in these research results formalises the results of Msweli-Mbanga and Mkhize (2007), and establishes sound empirical evidence that there is still a long way to fully realising the benefits associated with women's unique attributes in South Africa. Implications are that South African companies have a lot of work to do, as a result of an entrenched maledominant business culture, in order to ensure that women perform to their best.

In agreement with Baxter (2007), corporate South Africa should commit themselves to fast-tracking the advancement of women in the workplace by designing and adopting policies that will facilitate greater numbers of women in leadership positions. However, appointing women into leadership positions without good support mechanisms will destroy owners' wealth. Equally important is the creation of a supportive and enabling business environment for women to reach their full potential. This environment can be achieved through support strategies such as women-tailored training and development, partnerships and networking, and mentoring and coaching. The Business Women's Association in South Africa is one of the existing support structures established for business women.

\section{7}

\section{Conclusions}

The purpose of this study was to determine the impact of female business leaders in JSE-listed companies on the financial performance of those companies. Results of this study show that companies led by female executives do not outperform similar companies without female executives. Based on these results, a lot of work still needs to be done in order to realise special benefits associated with women unique attributes. In addition to appointing these females into executive positions, these appointed women need to be capacitated in terms of skills development and the creation of opportunities and a suitable working environment.

There are several limitations in this study. One of them is that only top companies by market capitalisation formed a sample size for this study. Although this kind of sample was necessary in order to control for the size effect which may have distorted the results of the study, the sample limits generalization in this study on small market capitalization companies. Another limitation is that, because the new Africa board's, the alternative exchange's, development and venture capital's companies were isolated owing to their different characteristics from those of the main board, results of this study cannot be applicable to these companies. Future research may be based on these isolated categories of companies within the JSE. Another limitation of this study is that it is short-term and it is believed that a longer-term study will paint a better picture of the financial performance of companies led by female executives. 
Endnote

We would like to gratefully acknowledge the two anonymous reviewers of this article and the editor of SAJEMS for their valuable comments about the article, and Norman Blight for his excellent proofreading skills.

\section{References}

AFFLECK-GRAVES, J.F., BURT, G.H. \& CLEASBY, S.J.M. 1998. The premium on acquisition in South African mergers: An empirical evaluation, South African Journal of Business Management, 19(4):55-60. BAXTER, G. 2007. Empowering women in the workplace - walking the talk. Celebrating Excellence in Organisations Magazine. A special edition of CEO magazine, Centurion: CEO Communications (Pty) Ltd: 80-81.

BERNADI, R.A. \& WEIPPERT, K.M. 2002. Signaling gender diversity through annual report pictures: A research note on image management, Accounting, Auditing \& Accountability Journal, 15(4):609-616. BODIE, Z., KANE, A. \& MARCUS, A.J. 2005. Investments, $6^{\text {th }}$ (int. ed.) New York: McGraw-Hill. BWA. 2007. Business Women Association's South African Women in Corporate Leadership Census 2007. Johannesburg: Dictum publishers (Pty) Ltd.

CLAES, M. 1999. Women, men and management styles, International Labour Review, 138:843-446. COTTER, D.A., HERMSEN, J.M., OVADIA, S, \& VANNEMAN, R. 2001. The glass ceiling effect. Social Forces, 80:655-681.

DIMOVSKI, W. \& BROOKS, R. 2006. The gender composition of boards after an IPO, Corporate Governance, 6(1):11-17.

FABOZZI, F.I. 1999. Investment Management, $2^{\text {nd }}$ edition, New Jersey: Prentice-Hall.

JOY, L. \& WAGNER, H.M. 2007. The bottom line: Corporate performance and women's representation on boards. [Online] Available at: http://www.catalyst.org/knowledge/files/Bottom\%20Line\%202.pdf [Accessed: 2007-10-2]).

LECK, J.D. 2002. Making employment equity programs work for women, Canadian Public Policy, May, 28:S85-S100.

MATHUR-HELM, B. 2006. Women and the glass ceiling in South African banks: an illusion or reality? Women in Management Review, 21(4):311-326.

MCDONALD, K.S. \& HITE, L.M. 1998. Exploring the glass ceiling: An exploration of gender differences in management-development experiences, Journal of Management Education, 22(2):242-254.

MSWELI-MBANGA, P. \& MKHIZE, H. 2007. The risk-adjusted performance of companies with female directors: A South African case, South African Journal of Economic and Management Sciences, NS 10(2):207-213. 